\title{
APPROACH OF SIX SIGMA METHOD TO CONTROL THE QUALITY OF WET MIX PRODUCTS IN THE CREAM MAKING PROCESS
}

\author{
Titik Koesdijati $^{1)}$, Yunia Dwie Nurcahyanie ${ }^{2)}$ \\ ${ }^{1,2)}$ Industrial Engineering, Faculty of Industrial Technology, University of PGRI Adi Buana Surabaya \\ Email : titikkoesdijati@gmail.com
}

\begin{abstract}
One of the process making a creamer is the process of mixing liquid glucose, oil, emulsion powder and water that produces liquid creamer (wet mix / liquid mix). The wet mix results often not match with the standard which can affect the results in the next process. This is the purpose of company to make improvements in controlling wet mix in order to decrease the number of wet mix failure produced. The method used in this research was DMAIC (Define, Measure, Analyze, Improve, Control). Previous data processing was using Seven Tools, with 3 of 7 tools which are the observation sheet (check sheet), pareto diagram, and fishbone diagram. Through data processing and analysis using DMAIC obtained 3 types of failure of semi-finished products (wet mix) which was wet mix as much as $38.8889 \%$, wet mix gross as much as $36.1111 \%$, and wet mix browning 25,0000\% and obtained sigma value at Level 3.87. Define is the stage of defining quality problems, and defined the cause. Measure is the stage of measuring the failure rate of the product. Analyze is the stage of quality improvement by analyzing factors causing product failure. Improve is an action plan to improve quality by eliminating factors causing product failure. Control is the last stage of the Six Sigma project that emphasizes the documentation and dissemination of actions that have been done.
\end{abstract}

Keywords : Wet mix, sig sigma, seven tools.

\section{INTRODUCTION}

In effort to improve product quality, company applies quality assurance system at each stage of the process. One of the stages of cream making is liquid mixing which is dissolving all components into water through a high shear mixer. Then add glucose syrup, oil and emulsifier. This process produces liquid cream (wet mix / mix liquid). Sometimes, the wet mix is often not according to standard, such as dirty wet mix, bad smell mix, and browning wet mix, which can affect the results in the next process. To solve these problems, a Six Sigma method is then used.

Implementation of the Six Sigma method through the DMAIC concept known as define, measure, analyze, improve and control cycles is expected to reduce the number of Wet Mix failures. This is very beneficial for the company because it reduces the costs wasted due to the failure of semifinished products (Wet Mix) which can reduce production costs and find out the factors that affect the product to fail.

The formulation of the problem in this study is how to analyze the causes of the wet mix product that fails at the stage of the liquid mixing process and how the proposed improvements to overcome the problem. While the purpose of this study is to identify the causes of wet mix products that fail at the stage of the mixing liquid process and provide suggested improvements based on the results of the study. Problems are limited to the process observed only on companies liquid mixing process.

\section{RESEARCH METHODOLOGY}

The research design was carried out as follows, shown in figure 1. 


\section{Tibuana}

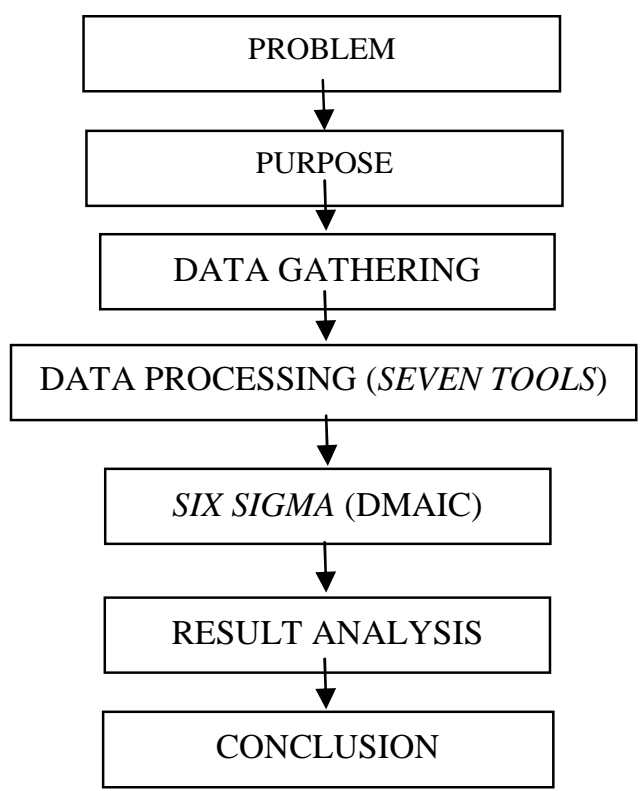

Figure 1. Research Design

By using this method of measurement it will be able to find out the quality characteristics of the wet mix that are good or bad, successful or failed. The 3 wet mix characteristics that are considered defective are dirty Wet Mix (there are insoluble particles), smelly Wet Mix (there is a foreign odor) and browning Wet Mix (color is not standard).

Data collection was carried out by observing the process of spray dryer into a cream product by determining 3 wet mix characteristics which were deemed defective namely dirty Wet Mix (there are insoluble particles), smelly Wet Mix (there is a foreign odor) and browning Wet Mix (color is not standard). This data is then processed through 3 out of 9 tools on seven tools, namely:

\section{Pareto Diagram}

Data taken, processed to find out the percentage of product types rejected by the formula:

$$
\begin{array}{lll}
\% \text { Damage }=\frac{\mathrm{A} \text { O T D }}{\mathrm{A}} \mathrm{D} & & \\
\hline \% \text { Wet Mix Browning } & =\frac{4}{1} \mathrm{x} \\
100 \% & =25,0000 \% \\
\% \text { Wet Mix Smelly } & =\frac{6}{1} \mathrm{x} \\
100 \% & =38,8889 \% \\
\% \text { Wet Mix Dirty } & =\frac{5}{1} \mathrm{x} \\
100 \% & =36,1111 \%
\end{array}
$$

Then it can be described in the Pareto diagram in figure 2. 


\section{Tibuana}

Journal of applied Industrial Engineering-University of PGRI Adi Buana

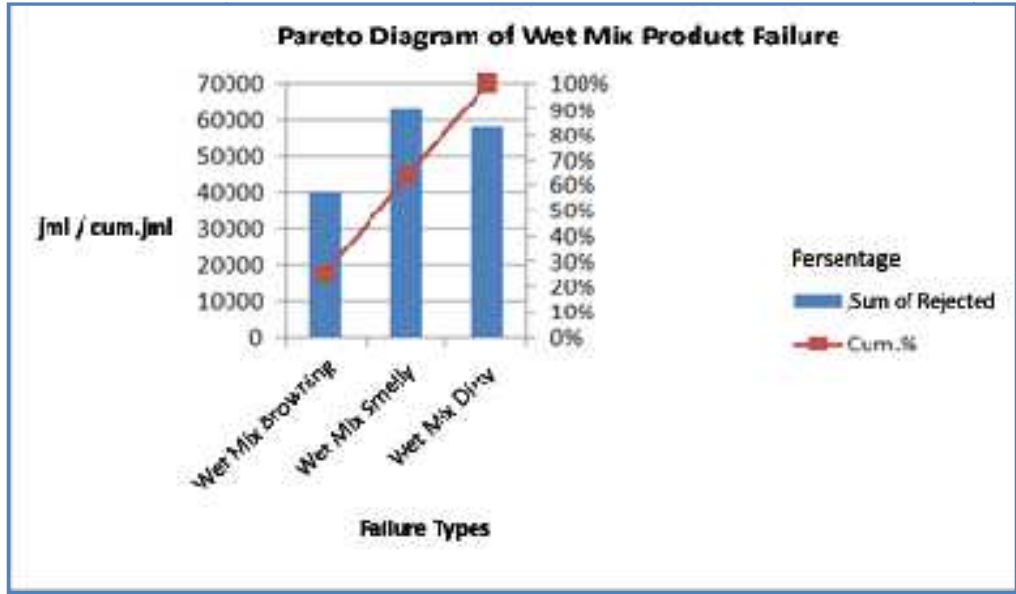

Figure 2 Pareto Diagram of Wet Mix Product Failure

2. Control Diagram (X-Bar and $R$ chart)

- Calculating the mean mean: $\mathrm{X}=4489$

- Determine the average range value: $\mathrm{R}=5611.25$
Determine the upper control limit (UCL) and lower control limit (LCL) to make a diagram $\mathrm{X}$ Chart Control and $\mathrm{R}$ Chart Control Diagram

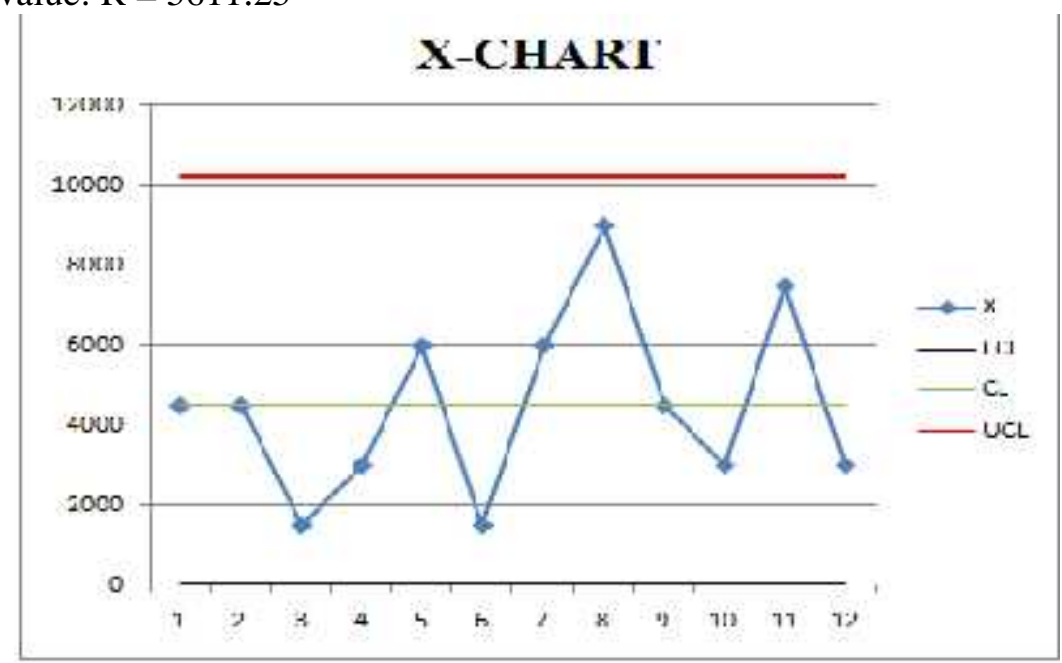

Figure 3 Control X Chart Diagram

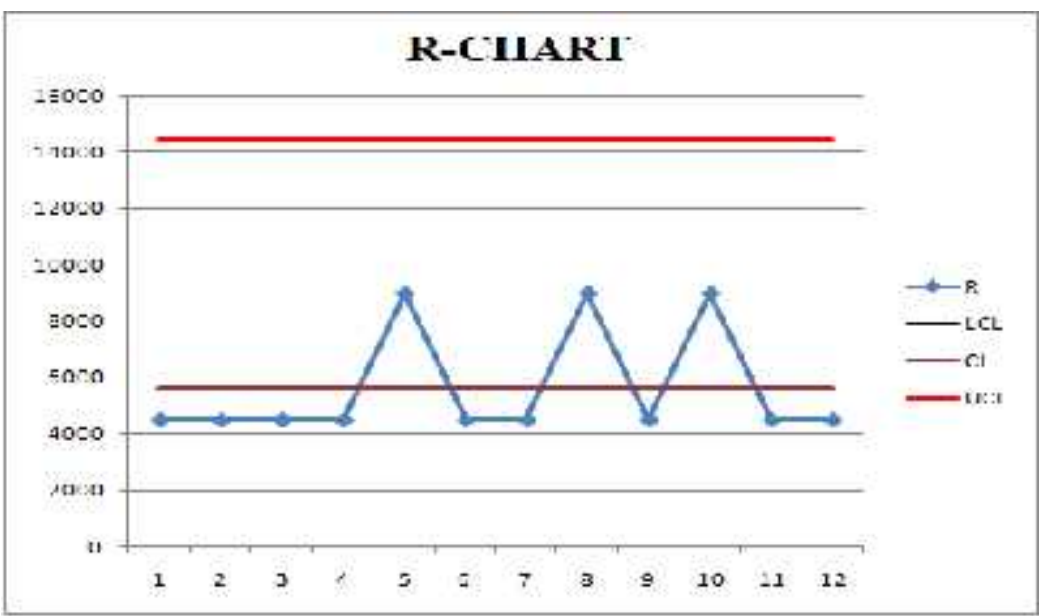

Figure 4 Control R Chart Diagram 


\section{Tibuana}

Journal of applied Industrial Engineering-University of PGRI Adi Buana

p-ISSN 2622-2027

$e$-ISSN 2622-2035

3. Cause and Effect Diagram

a. Wet Mix Browning

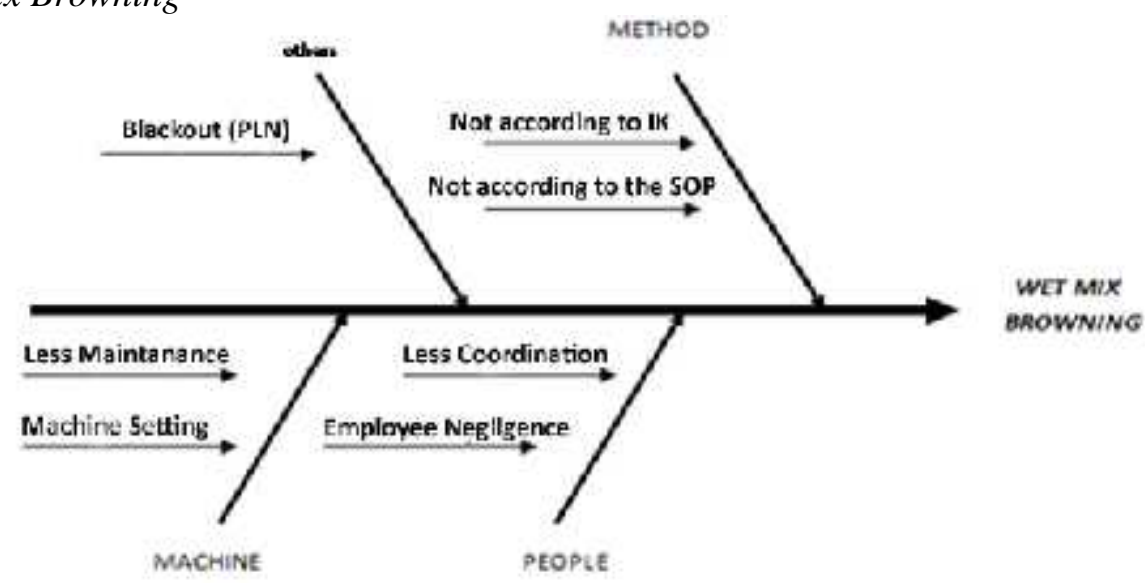

Figure 5 Cause and Effect Diagram Wet Mix Browning

b. Wet Mix Smelly

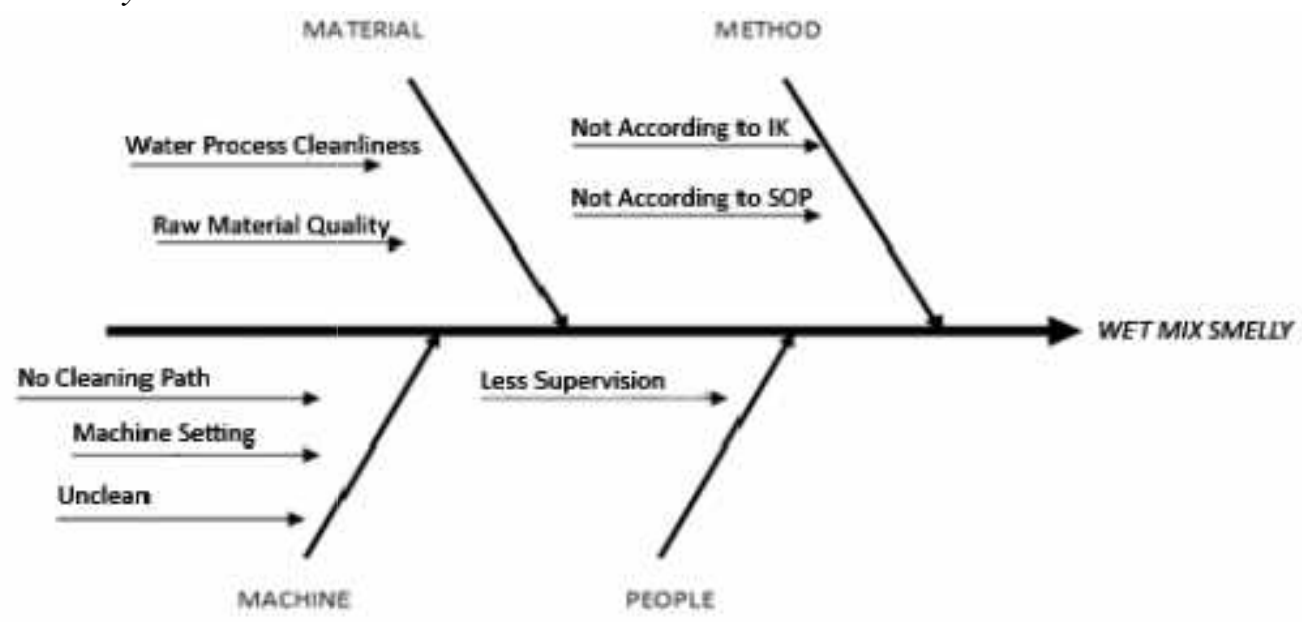

c. Wet Mix Dirty

Figure 6 Cause and Effect Diagram Wet Mix Smelly

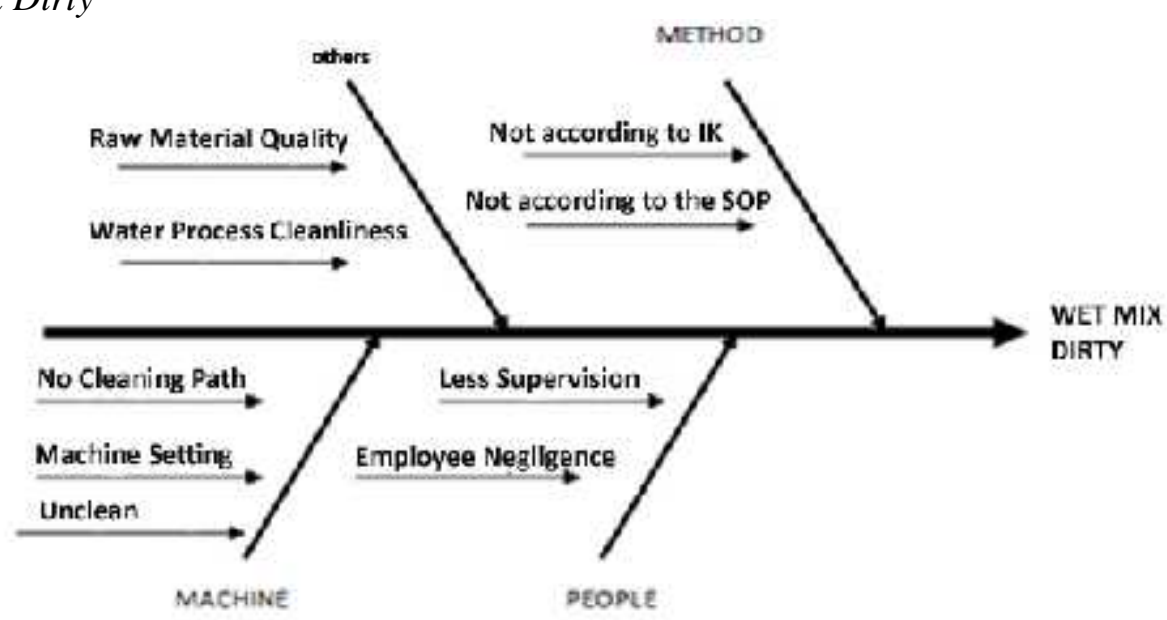

Figure 6 Cause and Effect Diagram Wet Mix Dirty

TiBuana, Vol.2, No.2, 2019|53 
Before carrying out the analysis phase, it is necessary to calculate DPMO so that the Defect per Million Opportunities (DPMO) can be seen when compared to the six sigma concept value, namely 3.4 product failures for every 1 (one) million products produced.

\section{Stage of Sigma and Defect Per Million Opportunities (DPMO) Measurement}

$$
\begin{aligned}
& \text { DPMO (week 1) }=\frac{T \text { l }}{T} \text { X } \\
& 1000000 \\
& \text { DPMO (week } 1)=\frac{1}{1} \text { X } 1000000 \\
& \text { DPMO (week } 1)=10380,62284
\end{aligned}
$$

Complete results until week 12 are presented in Table 1.

Table 1 Defect Per Million Opportunities (DPMO)

\begin{tabular}{cccccc}
\hline Minggu & Total Reject & Total Prod & $\begin{array}{c}\text { DPU=Total } \\
\text { Defect/Total } \\
\text { Prod }\end{array}$ & $\begin{array}{c}\text { DPMU=DPU } \mathbf{~} \\
\mathbf{1 0 0 0 0 0 0}\end{array}$ & Sigma \\
\hline DPU 1 & 13467 & 1297321 & 0,010380623 & 10380,62284 & 3,81 \\
DPU 2 & 13467 & 1279565 & 0,01052467 & 10524,67049 & 3,81 \\
DPU 3 & 4489 & 1400568 & 0,003205128 & 3205,128205 & 4,23 \\
DPU 4 & 8978 & 1342211 & 0,006688963 & 6688,963211 & 3,97 \\
DPU 5 & 17956 & 1423013 & 0,012618297 & 12618,29653 & 3,74 \\
DPU 6 & 26934 & 1369145 & 0,003278689 & 3278,688525 & 4,22 \\
DPU 7 & 17956 & 1409546 & 0,012738854 & 12738,8535 & 3,73 \\
DPU 8 & 26934 & 1319766 & 0,020408163 & 20408,16327 & 3,54 \\
DPU 9 & 13467 & 1221008 & 0,011029412 & 11029,41176 & 3,79 \\
DPU 10 & 8978 & 1373634 & 0,006535948 & 6535,947712 & 3,98 \\
DPU 11 & 22445 & 1387101 & 0,01618123 & 16181,22977 & 3,64 \\
DPU 12 & 8978 & 1378123 & 0,006514658 & 6514,65798 & 3,98 \\
& & \multicolumn{5}{c}{ Average } & 10008,71948 & 3,87 \\
\hline
\end{tabular}

From table 1, the DPMO value of product failure is 3.87 which is obtained for every 1 (one) million products produced.

\section{RESULTS ANALYSIS AND COMPLETION}

The analysis of these results is also used to find solutions in solving wet mix problems that failed in the process of making creamer.

\section{Define}

The three most potential causes of producing a wet mix are defined as follows:

a. Wet Mix is dirty (there are insoluble particles) that is there is insoluble solid in the form of small lumps of powder material.

b. Wet Mix smells (there is a foreign odor) which is a smell that is not in accordance with the existing wet mix quality standards. c. Wet Mix browning (nonstandard color) which is wet mix which tends to be dark (burnt / blackish).

Plans for actions to be carried out based on the results of observations and analysis of research:

a. Increased supervision of the workforce to be more thorough in running and monitoring the liquid mixing process.

b. Perform repairs and checks on the machine to make it more optimal and stable.

\section{Measure}

The number of semi-finished products (wet mix) produced from March 2017 to May 2017 is $16200801 \mathrm{~kg}$, and a failed product is found, it is suspected that the failed product derived from the three main causes of failure is $161604 \mathrm{~kg}$.

Because the X-bar Chart and R Chart are between UCL and LCL, the process 
capability is running well, so it is able to explain that the process capability is able to meet the desired tolerance limits, but strict controls are needed to keep the wet mix quality constant.

\section{Analyze}

The failure of semi-finished products (wet mix) is caused by machinery, employees, raw materials, methods and others. These factors are the main causes that affect the weaknesses of the liquid mixing process, causing a failure of the intermediate product (wet mix) which can be explained as follows:

a. Engine

The intensity of the use of a machine that almost never breaks causes the engine to become tired. Therefore what must be done by the company is more attention to periodic maintenance and repairs

b. Employees

Employee performance that is less than optimal will affect the operation of the machine. Therefore, for employees who appear to be less skilled in operating machinery, the employee is required to attend training or training held by the company.

c. Raw materials

The approach and management of raw materials must be done by the management of the company properly so that the raw materials received can be maintained quality.

d. Method

Quality control methods in the production process there are still parts that are not subject to intensive inspection, namely the water storage tank for the liquid mixing process.

The work method provided by the company greatly influences the smooth production process. With the existence of Standard Operating Procedures and Work Instructions that are applied by companies to regulate all parts involved in the production process and can reduce the failure of semi-finished products (wet mix). The more companies do not run the work method well the more likely the product is to fail.

e. Others (electricity outages)

Suddenly there is a sudden PLN electric extinguisher and the lack of power generator available makes the liquid mixing process hampered or dead. So that the raw material that has been processed becomes damaged due to the delay in the liquid mixing process. With the additional generator, it is expected to be able to back up the supply of electricity at a sudden power outage.

\section{Improve}

1. Measurement

1) Opportunity: Reducing the number of intermediate products (wet mix) that fail in the liquid mixing process by applying a more precise control system.

2) Damage: From $16200801 \mathrm{~kg}$ of products produced in March to May 2017 there are defective products of $161601 \mathrm{~kg}$.

2. Recommended improvement recommendations

1) Quality control in the liquid mixing process includes the machine. Machine supervision is carried out intensively and continuously. The machines are cleaned and repaired every day and machine testing is carried out.

2) The raw materials of powder received from selected suppliers are more accurate in order to get quality quality of wet products. In addition, the water tank cleaning process is carried out regularly so that the quality of the water used for the liquid mixing process is guaranteed quality

3) Make a check sheet for data collection of semi-finished products (wet mix) that fail on the liquid mixing process and good products.

4) Supervisors are responsible for the failure of their respective wet products as a result reported to the production manager. 


\section{Control}

It is the final stage of the Six Sigma project that emphasizes documenting and disseminating the actions taken including:

1. Perform maintenance and repair machines regularly.

2. Supervise raw materials in the form of RM powder and process water by the production employees so that the quality of the goods produced is of high quality.

3. Supervise the liquid mixing process

\section{CONCLUSION}

Based on the results of research and discussion, some conclusions can be drawn as follows:

1. The capability of the mixing liquid from March 2017 to May 2017 is $16200801 \mathrm{~kg}$. It can be said that the mixing liquid process during March 2017 to May 2017 has a good process capability. Because the $\mathrm{X}$ bar Chart and $\mathrm{R}$ Chart values are between UCL and LCL, so it is able to explain that the process capability is able to meet the desired tolerance limits, but strict controls are needed to keep the quality of Liquid Mixing stable. It can be seen also that the cause of the wet mix product that failed at the stage of the liquid mixing process by the company which was then entered into the Pareto diagram and the causal diagram is found in the machine, employee, raw material, method etc. (power outages).

2. Various actions and business proposals made by the company can overcome the failure of semi-finished products (wet mix) so as not to occur in the future, including by

5. REFERENCE

[1] Gaspersz, Vincent.(2001). Total Quality Management. Jakarta, Gramedia Pustaka Utama.

[2] Harry, Mikel and Richard Schroeder.(2000). Six Sigma: The BreakthroughManagement Strategy Revolutioning the Worlds Top
4. Recording periodic failure of the wet mix.

5. The total number of failed products is included in the SPV Daily Report carried out by employees.

6. The total number of failed products within a one-month period is included in the montly Report for the responsibility of the production manager to be reported to the director.

rearranging the schedule of maintenance of machinery and production equipment as well as possible, replacing damaged engine components, repairing the system employee recruitment selection that is more selective towards the production part operator, improvements to the periodic training system, conducts an evaluation of the supplier and does not hesitate to file a complaint with the supplier if there is an error, more rigorous supervision in the selection of raw materials used in accordance with company standards, and making cleaning lines in process water storage tanks, implementing a more clear and detailed Standard Operating Procedure (SOP), developing good communication between workers and classifying product failures based on their type, adding generator / power as backup electricity in the event of a fire electricity, and raises the level of employee awareness of the importance of maintaining environmental cleanliness around the factory.

Corporations. New York, RandomHouse Inc.

[3] Hidayat, Anang. (2007). Strategi Six Sigma. Jakarta, PT. Elex Media Komputindo.

[4] Koesdijati, Titik. (2017). Strategi Korporasi, Surabaya, Unipress 


\section{Tibuana}

Journal of applied Industrial Engineering-University of PGRI Adi Buana

p-ISSN 2622-2027

$e$-ISSN 2622-2035

[5] Miranda,(2002).DownloadInternet.w ww.bagiilmubagirizeki.wordpress.co $\underline{m}$

[6] Pande, P.S., Robert P. Neuman, Roland R. Cavanagh.(2000). The Six SigmaWays-How GE, Motorola, and Other Top Companies are Honing Their Performance. New York, McGraw-Hill, Inc.
[7] Pyzdek, T.(2001). The Six Sigma Handbook-A Complete Guide for Greenbelts,Blackbelts, and Managers at All Levels. New York, McGraw-Hill, Inc.,

[8] Tannady, Hendy.(2015). Pengendalian Kualitas. Jakarta, Graha Ilmu 